\title{
Notas para un estudio sobre poesía noguaya
}

Cielito, cielo que sí. No se necesitan Reyes Para gobernar los hombres

Sino benéficas leyes...

Bartolomé Hidalgo.

(1788-1822).

$\mathrm{F}_{\mathrm{N}}^{\mathrm{N}}$ los principios de la poesía rioplatense, por allá por los umbrales de las libertades políticas, asoma lo popular con la fuerza autóctona. Es natural que así sea, pues los llamados hombres cultos están sólo preocupados por la pérdida de las sinecuras de este nuevo mundo. $\mathrm{Y}$ los hombres que hacen las guerras libertadoras son rústicos soldados, y en este caso, gauchos, vale decir, guachos, así no más, hijos de la necesidad de algún soldado del rey y de alguna criollita humilde. El gaucho tiene sólo madre y después sale al campo, ya mocito a "cuerear", a acumular las fortunas del corambre para los españoles, los lusitanos y los ingleses. Cuando despunta Artigas, y desenvaina su sable en la Banda Oriental, todo el gauchaje sale tras él, como un solo cuerpo. Con él, van los negros traídos del corazón del Africa, que ya se han hecho a la vida de las colonias, los criollos visionarios, ejército errante, trashumante, atravesando tierras sin fin, hasta hacer depuntar la aurora libertadora. Es preciso hacer notar esta circunstancia popular que da principio a la vida de la República. Como en ningún otro país del Continente, en éste se nace en la dureza y se vive en la flacura de los atavíos. Es pueblo, pueblo puro el que va a la cabeza y es pueblo, solamente 
pueblo, el que compone los ejércitos. $Y$ en este pueblo movedizo y guerrero por circunstancias históricas, aparecen los rápsodas del guitarrón, que lo cuelgan a un lado de la montura, mientras al otro, golpea el sable.

Bartolomé Hidalgo, forma parte con su cuerpo y su alma del gran éxodo del pueblo oriental. Desde él, asoman los "cielitos", especie de romancillos cantados, voz de ánimo para las huestes enlutadas, aquellas tantas familias que con gallinas, perros, caballos y cerdos, amén de ellas y adminículos de cocina seguían al Jefe, por toda la Banda en un peregrinaje hondo y erguido de altivez.

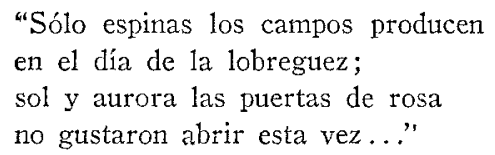

Así cantaba don Bartolomé, entre leguas y leguas cansinas y polvorientas. $Y$ con él, iban cantando la patria oriental, sudorosa a caballo y correaje, ardida de pan escaso y merienda ayuna. Después, después vino la República. Herida por su propia democracia, ve alzarse un caudillo tras otro, subir una divisa tras otra a la altura de los gobiernos. Viene la gran racha romántica, prestada incuestionablemente, tal como nuestras culturas actuales, sedimentadas sobre los estratos europeos, alzando las voces de los poetas como el giro igual de los mismos tonos:

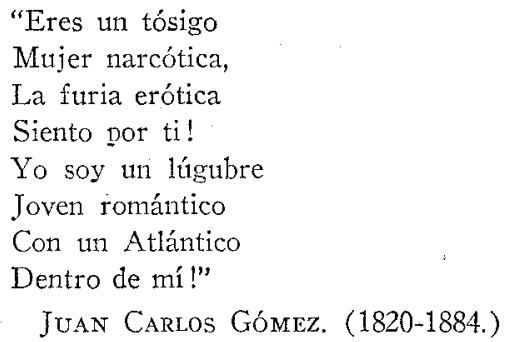

Lo popular quedó allí, arrinconado en las casas de las barriadas humildes, lindando ya con las arboledas, casas iluminadas por candiles de sebo, donde retumba de vez en cuando el tamboril y se elevan las voces negras en rituales canciones. El "cielito" alcanzó la mayoría de edad en las revoluciones y después se fué guardando 
por todos los rincones de Montevideo, para dar paso a engolados caballeros, jurisconșultos y letrados, prohombres de la nación recién parida, que como Juan Carlos Gómez, copiaron de pe a pa, las modalidades de una Francia que trataba de captar, para su desarrollo, hasta el aliento del Nuevo Mundo.

Por eso es que la sorpresa de Julio Herrera y Reissig ${ }^{1}$ es doblemente grande. Emerge este poeta del Montevideo semicolonial, con una tónica distinta. Es el modernista en la voz, romántico en el gesto, con aquel romanticismo decadente que asoló a América, después de la libertad. En Julio Herrera se junta el gesto ampuloso y declamatorio con el atuendo oscuro, la capa voladora, el chambergo, la solitaria torre de marfil, llamada por él la torre de los panoramas, lóbrego cuchitril, empinado junto al río de la Plata, por allá por la ciudad vieja, de calles estrechas y en declive, matizadas por el coloniaje todavía vivo. Los versos de Herrera y Reissig, inician el período de la poesía culta uruguaya. Abren la página histórica de esta expresión literaria con sus audaces esdrújulos de "Soneto en llave de U' y conmueven socialmente al público poco acostumbrado a bizarrías de esta clase, gentes adormecidas por el opio romántico. Y además poco dados a las renovaciones. Herrera irrumpe en el paisaje plácido como un violento temporal. Su modernismo alimentado con visiones particularmente barrocas se manifiesta en sonetos como el que leemos a continuación:

"Con pompas de brahamánicas unciones, abrióse el lecho de tus primaveras, ante un lúbrico rito de panteras y una erección de símbolos varones... Al trágico fulgor de los hachones, ondeó la danza de las bayaderas, por entre una apoteosis de banderas y de un siniestro trueno de leones. Ardió al epitalamio de tu paso, un himno de trompetas fulgurantes... Sobre mi corazón los hierofantes ungieron tu sandalia, urna de raso, a tiempo que cien blancos elefantes entoscaron su trompa hacia el ocaso."

("Epitalamio ancestral") 
Herrera recoge el llamado barroquismo americano mejor que ningún otro poeta uruguayo. Para este ser amante de lo exótico, se construyeron las cornucopias y los altares; puebla su poesía con visiones mitológicas, aspira unánimemente con ella a vivir fuera del medio natural donde edifica toda su creación. Es comprensible. Su medio nativo le es adverso. Junto a él, un reducido grupo de escritores ensaya las nuevas voces propias, entre la estulticia de los fenicios comerciantes montevideanos. Herrera se aísla, rehuye el contacto social, lucha y grita solo. Ningún gobierno le acuerda un consulado europeo, al que aspira secretamente; pero es demasiado orgulloso para solicitarlo. $Y$ allí está su vida, recoleta en cuanto al yantar, pero riquísima de pecho adentro. Como buen romántico aspira a un mundo hecho por él. Como depurado modernista, huye del lugar común que supone el romanticismo. En esta fuga, descubre el gran huidor lo nacional y lo incorpora sin mayores regodeos a su obra, tomando por primera vez en la historia de la literatura uruguaya, imágenes y tipos diferenciados del medio montevideano. ${ }^{2}$

Inmediatamente después del fulgor de Herrera, aparece en el escenario poético una delicada poetisa uruguaya, María Eugenia Vaz Ferreira, ${ }^{3}$ voz profunda y solitaria, es una de las escasas poetisas nuestras que no resbala en sensoriales composiciones. Al contrario, un cierto misticismo, una contención sabia orienta sus pasos en la poesía. Podríamos decir de ella, que es el antecedente más directo de nuestra Gabriela Mistral, pues sin poseer el lanento hondo de la chilena -lamento justificado frente a una naturaleza híspida y a una vida social violenta-, María Eugenia, como terminamos por llamarla todos a poco de leerla, construye sus mejores páginas en una especie de éxtasis superior que se debate entre las ataduras mortales. A veces Sor Juana Inés guía su mano para dirigirse -estamos en los albores del siglo $\mathrm{xx}$-, a sus semejantes:

\author{
"Alna mía \\ que tornas al viejo lar \\ con la red seca y vacía \\ de las orillas del mar, \\ que en la plenitud del día \\ no te atreviste a arrojar." \\ (Fragmento de "Barcarolas de un escéptico").
}


Sorprende al lector ejercitado, la agilidad de las imágenes que refrescan la a veces austera emoción de la autora. Creemos que pocas veces se ha dado en América Latina tal caso de maestría intuitiva, de sensibilidad sobrecogida y expresada con tal talento. Además, una sociedad tal, que como el Montevideo de 1900, soportara una mujer con inteligencia artística que además la lucía ampliamente.

Su polo opuesto en cuanto a expresión, lo constituye otra mujer. Esta es Delmira Agustini. ${ }^{4}$ Toda materia temblorosa, toda boca de amor que suspira y gime, Delmira constituye otro de los ángulos soportales del trío femenino que para la poesía continental ha dado el Uruguay.

En Delmira Agustini, se volcó la naturaleza más poderosa y fué expresada sin pudores hipócritas. Cantó al placer, al amor, pero al amor sin trabas de ninguna especie. Ella recibió la herencia modernista y sin innovar personalmente la escuela, incorporó a ella una potencia personal pocas veces dada por una mujer. Una sinceridad sólo consecuente con la poesía le permitió expresar sentimientos generalmente, aún en nuestros días, cuidadosamente relegados a la intimidad más profunda. Es difícil explicarse, salvo como un fenómeno de la naturaleza, la extraordinaria floración poética de Delmira. Entre muchas poetisas - ya las había por aquel tiempo-, se exhibe sola, se le advierte cantando en el medio del estupor de quienes no podían concebir ni al modernismo ni a una mujer modernista.

Para una mejor ordenación de estas notas, hemos dividido la historia de la poesía uruguaya en cuatro etapas. La primera abarca desde Bartolomé Hidalgo, o sea, la Independencia uruguaya hasta Delmira Agustini, que cierra el principio del siglo. Desde luego, muchos nombres de poetas existen en este ancho lapso, pero, en verdad quienes 10 significan, son sólo los nombrados. Posiblemente algún nacionalista furibundo pueda reprocharme la exclusión en este capítulo del poeta patriótico Juan Zorrilla de San Martín. Qute se me excuse esta omisión absolutamente intencional, pues, dentro de un juicio crítico que tome en cuenta fundamentalmente la poesía y no circunstancias adjetivas a ella, no tiene cabida el poeta mencionado. Sí, en cambio, los nombrados que representan efectivamente un aporte de la poesía uruguaya a la poesía de habla castellana. 
¿De donde nació en este pueblo pacífico y eglógico, ese volcán efervescente llamado Sabat Ercasty? ${ }^{5}$ Llegó a la poesía uruguaya de golpe, como un tornado que vuelca todo a su paso. Es imposible leer en este país sin encontrar en alguna parte clavada la voz de este gran maestro de generaciones, cuya expresión ha tenido una honda repercusión en todo el continente. Posiblemente Carlos Sábat Ercasty sea el poeta uruguayo cuya obra se ha difundido más y es encontrada en muchos que ignoran a su maestro. Modesto y sencillo, Sabat mismo no imagina lo que ha penetrado en la lengua castellana. Acá no podemos buscar las raíces autóctonas, porque todas las raíces que han conformado la nacionalidad de este pueblo se encuentran en Europa. Así como sus escuelas y tendencias, los nombres paternos se afincan en las viejas tierras de España, Francia e Italia, generalmente. Porque para hablar de Sabat, hay que ir indudablemente a sus ancestros. De otro modo, no podemos comprender una floración tal, una expresión tan vigorosa y personal en un hombre del medio uruguayo. Sabat, es a veces, casi excesivo. Brotan de él las invocaciones, las imágenes, arrasa con los ya un poco viejos moldes del modernismo para edificar tna poesía caprichosa que sigue sólo el ritmo personal impuesto por su autor. Ritmo que está únicamente sujeto por una condición: expresividad:

"los vientos resalados danzan, corren, asaltan..."
"Ah, el furor de la música, la salvaje potencia,
los anhelantes gritos, los acordes crispados
de las olas violentas de vientos y de sales ..."
"El sol abre en las nubes grandes puertas azules..."

("Alegría del mar").

Sabat Ercasty ama las grandes extensiones, la despolarización del lenguaje y, a la vez, es el primer poeta del Uruguay donde en virtud de una castigada cultura y de un humanismo acendrado y sólido, aparecen matices filosóficos en su verso. Los anteriores sólo son instinto poético ejercitado en la medida que el tiempo, la época restringida de suyo lo permitía. Sabat, construye un universo personal. Luminoso universo, dadivoso y amplio para todas las especulaciones. Es un gran panteísta, que ama desaforadamente todo cuanto alumbra, se mueve, brilla. $\mathrm{Y}$ al fondo de la poética excepcional de este poeta extraordinario, una llama de inteligencia, 
vigila ardientemente toda la forma, aparentemente descuidada que cuida celosamente el orden de su pensamiento. Lean este elogio a la naturaleza de las cosas:

"iPresencia de la amada!

Su marcha bajo la luna es el origen de los violines y las arpas.

Su cuerno es el sueño sensible, su interior es la revelación antes de la revelación.

Su reposo es el silencio de las estrellas, su movimiento es la marcha de la noche.

Su amor es la columna de la luz, su aceptación es el entendimiento sobre la eternidad, su éxtasis es la túnica del espíritu sobre el pensamiento divino".

(Fragmento vir del "Cántico de la presencia".)

Quizá un exigente y minucioso descubridor de influencias estéticas podría hallar en las mejores páginas de los románticos ingleses y alemanes fuentes nutricias para el talento expresivo de Sabat. O el parentesco resultará simplemente por raíces afines, por búsquedas y ejercicios de los grandes textos de la vida. La verdad es que Sabat. Ercasty, es un fenómeno poético pocas veces dado en América, sin necesidad de compararle con Walt Whitman, cosa que a menudo sucede al nombrar a Sabat. Poeta mayor, quizás el mayor de la historia literaria uruguaya, agrega a su talento expresivo los dones de una cultura vasta -incluso es lector de las culturas prehispánicas-, y de una sencillez también pocas veces vista entre escritores bastante pagados de sí mismos.

Sobradamente conocido en todos los países de habla castellana es el nombre de Juana de Ibarbourou. ${ }^{6} \mathrm{La}$ autora de tantos versos que aprendimos desde niños, es la tercera gran poetisa del Uruguay: Tercera en cronología, pues su expresión literaria no cede en un sólo punto a las voces de sus antecesoras, María Eugenia Vaz Ferreira y Delmira Agustini. Juana se caracteriza por un verso de gran frescura, por imágenes sabiamente distribuídas y de una fluidez que es un delicado susurro para el espíritu. Su popularidad es vastísima. Su señorío es proverbial. El verso fluye de ella, con una limpidez raras veces conseguida, sobre todo en la época en que muchos poetas buscaban la abstracción y los elementos metafísicos como una vuelta a la normalidad desquiciada por la primera guerra mundial. Juana de Ibarbourou, en medio de un universo caótico, supo 
conservar el equilibrio de la sencillez. No se deja tentar por la facilidad de lo obscuro, terreno donde resbalan casi todos los poetas de su generación y entrega páginas antológicas para la literatura castellana.

Así como el Uruguay dió a Francia tres poetas, ésta dió al Uruguay, por lo menos, uno. Este es Carlos Rodríguez Pintos, ${ }^{7}$ educado en la Sorbonne, hombre de formación humanística excepcional, discípulo ferviente de Valéry, el gran poeta de la burguesía francesa. De Francia, trajo a las riberas del río de la Plata, Rodríguez-Pintos, una visión formal decantada. El fondo de su pensamiento lírico es europeo. Pero, al contacto con la vida natural de este país, estrechando vínculos con su realidad social, aquel joven poeta que escribiera versos parnasianos, fríos por fuera y ardientes por dentro, se fué trocando en un melancólico y escéptico trovero que llega a la elegía más pura en su "Canto de amor" escrito en octavas reales en 1946. En Rodríguez-Pintos, prima la forma exquisita. O si no, cuando la exasperación le acomete, es capaz del ultraismo. Todo se agiliza bajo su pensamiento que busca la renovación interior, creyendo muy poco y amando mucho - 1955-, es: "Memoria funeral del héroe" y "Tres sonetos a una lágrima".

Emilio Oribe ${ }^{8}$ buscó las disciplinas del pensamiento para encarar su necesidad de belleza. De los secos estudios filosóficos, de los austeros textos hipocráticos, Oribe emergió envuelto en un aura estética, solitaria y ajena al tráfico literario. Ausente de los convencionales signos internacionales para designar las emociones humanas, transmuta en su alma secretos perfumes que él sólo regusta. Su poesía, más que expresión de belleza directa, deja la sensación de la profundidad del conocimiento. Unico en Uruguay dentro de su personalísima forma plantea Oribe los problemas del ser, con una honda melancolía que le viste de tristeza.

Julio J. Casal es otro poeta uruguayo de formación neta europea. Su verso es semejante al de Juan Ramón Jiménez. Fresco, alado, juega con las imágenes en una tesitura tierna, humanísima:

"Ni tú ni yo, ni el viento...

No sabemos nada.

Tú que lo esperas todo 
yo, que no espero ya.

$Y$ el viento que entra

en las casas y mira..."

("Poemas".)

\section{Los nuevos}

Con Casal se puede cerrar esta puerta de la literatura uruguaya que florece desde 1900 en adelante. E1 mundo ha variado de posiciones durante esta etapa. El Uruguay ha soportado guerras civiles, se ha cambiado el curso de la vida ganadera del país y nuevos elementos de cultura se aportan a su desarrollo. Los cambios económicos que transforman la estructura de las naciones, también transforman y renuevan sus moldes artísticos. Lo que era modernismo con Julio Herrera y Delmira Agustini, lo que era nueva tendencia filosófica en Sabat Ercasty y Emilio Oribe, es distinta visión del mundo en sus colegas de ahora. Abramos este nuevo capítulo de la poesía uruguaya, situando un nombre, muy respetado y conocido en los países de habla castellana. Se trata del pedagogo, novelista y poeta, Jesualdo. ${ }^{9}$

Si bien para situar justamente a Jesualdo, habría que ir hacia la novela, terreno donde indiscutiblemente no tiene competidor en su país - recordamos solamente Vida de un maestro-, no es posible desconocer el aporte hecho por este escritor a la poesía del país. Este se descompone en varios libros de poesía. Nos referiremos sólo al último, Elegía autobiográfica, para situarle en el terreno poético.

El acucioso crítico y ensayista Zum Felde, coloca a Jesualdo, como descendiente de Mallarmé y de Apollinaire. Pero del estudio de su expresión resulta que este autor, considerado superrealista por el crítico mencionado, incorpora elementos netamente realistas a su obra, fundamentando su actitud lírica en un convencimiento estrictamente racional sobre el ser humano. Jesualdo, que en sus primeras obras de poesía, se dejaba llevar por las aguas de una ciega melancolía adolescente, sale ahora, maduro y entero, con su voz varonil donde se juntan y conjugan muchas voces humanas. Cuando deja vagar alguna queja amarga en sus líneas, es para sobreponerse. Veamos cómo canta al amor: 
"Este dulce exilio que en la vida existe $y$ que el amor le da tierra joh, morada fugaz!, tuvo en mi pena luz abierta y triste, y en su paz, toda mi guerra.

Fugitivo enamorado en todo puerto no creí más que en el amar ioh, morada falaz! más justo en medio del hombre vivo y muerto recién lo pude cantar."

(Fragmento $\mathrm{v}$ de "Tiempo de amar y tiempo de padecer en el amar, Elegía autobiográfica".)

Jesualdo representa y significa una tendencia en la poesía uruguaya actual. Tendencia que tiene pocos representantes en el país, debido a razones extraliterarias, fundamentalmente razones económicas, pues este hombre que escribe versos con tal punzante sentido de la realidad, ha avizorado más allá del horizonte limitado que circunda a la mayoría de los poetas rioplatenses más dedicados al cultivo de la forma que del fondo de los fenómenos. Su rica experiencia de maestro primario - es autor de varios textos pedagógicos de gran valía-, no sólo le ha vertido conocimiento científico sino y además como cosa muy importante, lo puso frente a frente con los más agudos problemas humanos indicándole normas de pensamiento donde la pasión se funde estrechamente con el conocimiento.

El simbolista Juan Cunha Dotti ${ }^{10}$ emerge como un oscuro cantor de cosas humildes. Incorpora a la poesía uruguaya, cierta actitud desaprensiva por la forma y una melancolía romántica al fondo de su expresión.

De nuevo nos encontramos con una voz femenina. Sara de Ibáñez ${ }^{11}$ aparece publicando un libro prologado por Neruda, en 1940. "Canto" descubre a una poetisa fina y delicada, cuya expresión se afinca en'las raíces más fuertes del idioma. Al leerla se advierte cuán profundamente han cavado en su espíritu los clásicos castellanos y cómo el talento personal de Sara de Ibáñez, tamizó esta influencia modernizándoles y entregándoles a través de una versión agilísima a un público que desconocía la presencia de tan alta representante de la poesía. Cabe hacer mención de sus liras, ya re- 
cogidas en antologías, por la depurada forma y el delicado pensamiento que las anima:

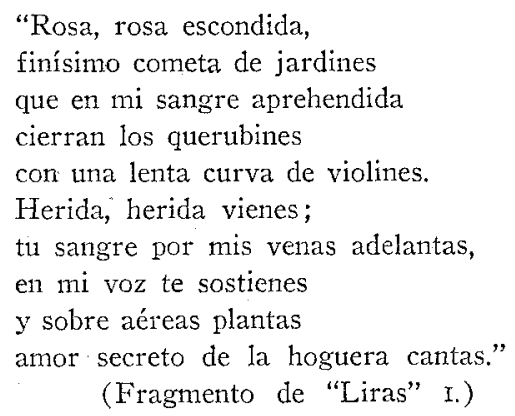

Sara de Ibáñez tomó del modernismo todo lo que esta escuela podía darle a su venero clásico. Uno y otro, ganaron en la voz de esta admirable poetisa. Algunos críticos han determinado cierta tendencia marmórea, cierto regustamiento de la forma por la forma en su poesía. No estamos de acuerdo con ellos. Animada de un alto sentido poético, Sara de Ibáñez, ha remozado lo clásico, ni más ni menos que García Lorca, con el romance. Los tercetos de Sara de Ibáñez, demuestran una maestría que escasos poetas uruguayos han alcanzado. En este sentido, digno también de mencionarse es el "Canto a Montevideo" premiado en el certamen conmemorativo del primer centenario del Certámen Poético, celebrado en Montevideo el 25 de mayo de 1941. Entre cincuenta composiciones presentadas obtuvo el premio Sara de Ibáñez, con su depurado poema, compitiendo con las más altas figuras de la poética rioplatense.

De 1940 en adelante ya es posible determinar en la poesía uruguaya la presencia de nuevas tendencias. A consecuencia de la guerra civil espar̃ola, sentida hondamente por este pueblo insobornablemente democrático y continuada en el espíritu nacional por la segunda guerra mundial, muchos valores se han trastrocado, muchos conceptos se han derrumbado. Las viejas escuelas filosóficas se declaran en quiebra ante la barbarie nacida de su descomposición. La economía colectiva y la particular, reciben también el choque material del cambio. $Y$ nuevas formas se presentan reflejadas en 
los poetas más jóvenes que nacen a la vida presenciando este derrumbamiento sin paralelos en la historia de la humanidad.

Muy jóvenes todos, no podemos opinar sobre la madurez de su obra. Esta, se presenta en dos grupos, dos tendencias, bien definidas, bien determinadas por la firmeza del acento de todos. Incuestionablemente, pese a ser semidesconocidos todos ellos, cada uno tiene su talento personal y aporta a la literatura rioplatense voces propias. El resto, lo determinará el tiempo. Uno de los más popularizados es Denis Molina. ${ }^{12}$ Es también quien más singtularmente se coloca en un extremo de la corriente existencialista.

Junto a él, podríamos situar a la poetisa Idea Vilariño, ${ }^{13}$ cuyo amargo y profundo acento conmueve dolorosamente. Esta poetisa ha publicado ya cuatro volúmenes de poesía. Es personal y talentosa. Podríamos reprocharle su excesivo pesimismo que no condice en absoluto con la realidad de la vida rioplatense. Suponemos que en ella actúan fuerzas inconscientes, légamos de romanticismo a pesar de lo moderno de sus poemas.

Carlos Brandy ${ }^{14}$ evoluciona rápidamente de un anegado existencialismo hacia una poesía realista y madura. Su tónica compuesta en un principio por voces oscurecidas de angustia, ha ido cediendo el paso en libros posteriores hacia un ámbito más humano y ancho. Saúl Pérez ${ }^{1.5}$ constituyó una sorpresa, publicando en 1950, a los 18 años de edad, su obra Homo ciudad, extenso poema a la urbe, prologado por Jesualdo, donde su autor con un penetrante talento recoge todo el interior y exterior de una capital, moviendo por dentro de este escenario al hombre, como un desesperanzado animal de costumbres.

$Y$ finalizamos esta rápida síntesis de la poesía uruguaya, con el nombre del poeta joven más realista y conseguido de todos. Se trata de Ariel Badano, ${ }^{16}$ autor de Cantos generales en 1947 y Voces del hombre en 1949. Como hemos afirmado en más de una oportunidad, Badano es uno de los poetas mejor dotados de la juventud del Uruguay actual. Realista, del mejor cuno, ha incorporado a su poesía con gran talento expresivo la tónica de grandes maestros americanos, como Neruda y Vallejo.

Es difícil y además, anticientífico, predecir destinos poéticos. Sin embargo, estamos ciertos que los poetas jóvenes nombrados ya 
están incorporados a la gran poesía uruguaya actual. Su obra pese a ser escasa, refleja con exactitud, dotes generosas.

Quisiéramos haber situado críticamente la producción poética uruguaya, en relación con la obra de otros pueblos latinoamericanos. Para esto, era preciso apartarse un tanto de la poesía misma e investigar en otros campos como el económico, que tanta importancia posee en el desarrollo artístico de las naciones. Esta investigación habría supuesto un ensayo de voluminosa factura. Además, en este instante de nuestro continente, todas las bases económicas de los pueblos que le componen, vacilan y se resquebrajan bajo el impacto de una política internacional zigzagueante. Nunca como ahora, asistimos a tanta crisis de valores consagrados y a tanta elevación -esperemos momentánea-, de falsos valores que aprovechan en forma oportunista y demagógica el proceso ascensional de los pueblos latinoamericanos. De todo el caos en que se debaten nuestras pequeñas naciones, surgirán indudablemente grandes poetas, poetas épicos y realistas, pues ésta es la tendencia central de países explotados por potencias mayores. E1 Urugtray, particularmente viaja atrasado con relación al desarrollo social de otros pueblos latinoamericanos. Su gran standard de vida, sus condiciones económicas de mayor solvencia internacional, por poseer una producción sólidia y un mercado seguro, han permitido que los escritores uruguayos, a diferencia de la mayor parte de los escritores de Latinoamérica, regresen siempre a las pequeñas formas individuales, cerrando las puertas de su obra a los grandes movimientos humanos.

Por todas estas razones consideramos aventurado entrar a comparaciones que podrían ser refutadas a poco andar el tiempo. Pero indudablemente, estas breves notas, no estarían completas si 110 hiciéramos mención de este problema de fondo de la literatura uruguaya. Su poesía se encuentra evidentemente en crisis. Obedece esta estagnación a circunstancias sociales. No advertimos, después de Sabat Ercasty, al gran poeta uruguayo, cuyo peso sea notorio dentro de la poesía castellana. Prima un tono menor, una búsqueda incesante dentro de los más viejos moldes del idioma. En su vasto panorama de revistas de indole literaria, es posible leer frecuentemente sonetos escritos por poetas o poetisas jóvenes con una ciega determinación hacia los pequeños problemas personales. 
Existe además una supervivencia de poesía gauchesca, escrita por poetas cultos, lo que constituye un doble error, pues lo respetable de la poesía popular es precisamente el estar hecha por quienes pertenecen integralmente a los fenómenos de la naturaleza y les describen o les viven en responsabilidad. Esta poesía gauchesca, pseudo popular, ha tenido y tiene cultores que la continúan prodigando como una débil muestra folklórica, en un país donde las sucesivas capas de emigrantes borran rápidamente las huelias de los antepasados.

$\mathrm{Y}$ así, podemos cerrar estas notas, someras, donde indudablemente se han omitido nombres en homenaje a la brevedad. Ninguno importante para la poesía. Los grandes cultores de la poesía en este país, están presentes. $Y$ además, aquellos cuyos nombres son la esperanza de la poesía del futuro. Aquellos, cuya juventud cronológica y de expresión, permite abrigar esperanzas de una gran poesía del futuro.

\section{Julio Moncada}

\section{$\mathrm{NOTAS}$}

1 Julio Herrera y Reissig. Obras: Aguas del Aqueronte, Pascuas del tiempo (poemas), 1900. Los maitines de la noche, Las manzanas de Amarylis, 1902. La Vida (conferencias), 1903. Los éxtasis de la montaña, 1904. El alma del poeta (epistolario), 1905-1909. Poemas violetas, Sonetos vascos, Opalos, 1906. Atomos, El renacimiento de España (prosa), 1907. La sombra (teatro), Ensayos sociológicos, 1909. Además, edición de obras completas que incluye Los éxtasis de la montaña, Las pascuas del tiempo, etc., etc.

2 Soneto recogido por Torres-Ríoseco en La gran Literatura Iberoamericana, pp. 138.

3 María Eugenia Vaz Ferreira. Obras: Póstuma: La isla de los cánti$\cos , 1925$.

4 Delmira Agustini. Obras: El libro blanco, 1907. Cantos de la montar̃a, 1910. Los cálices vacíos, 1913. Obras completas publicadas por el Ministerio de Educación del Uruguay, en 1939.

5 Carlos Sabat Ercasty. Obras: Pantheos, 1917. V. Basso Maglio (ensayo crítico), 1920. Poemas del hombre, 1921. Eglogas y poemas marinos, 1922. Poemas del hombre, 1922. Vidas, 1923. El onelo de la noche, 1925. 
Los juegos de la fuente, Los adioses, 1929. Poemas del hombre, Julio Herrera y Reissig (ensayo crítico), 1930. Lírida, 1933. El demonio de don Juan (poema dramático), 1935. Poemas del hombre, 1937. Máximo Gorky (ensayo crítico), Himno a Rodó y Oda a Rubén Dario, 1938. Geografía: En el rio Cebollatí, 1939. Oda a Luis Gil Salguera. Verbo de América: Discurso a los ióvenes, Cántico desde mi muerte, 1940. Artemisa, 1941. Romande de la soledad, 1944. Himno universal a Roosevelt, 1945. Himno a Artigas, 1946. Las sombras diáfanas, Poemas del hombre, Oda a Eduardo Fabini, 1947. Retratos del fuego: Castro Alves, Poemas del hombre, 1948.

6 Juana de Ibarbourou. Obras: Las lenguas de diamante, 1919. El cántaro fresco, 1920. Raíz salvaje, 1922. La rosa de los vientos, 1930. Estampas de la Biblia, Loores a la Virgen, 1934. Ha publicado, además, breves relatos en prosa.

7 Carlos Rodríguez-Pintos. Obras: Distancias y un poema en el océano, Columbarium, Dos oraciones a la Virgen (en colaboración con Rafael Alberti; Dos poemas (en colaboración con Manuel Altolaguirre); Suicidio, Canto al cielo de América, 1942. Canto de amor, 1946. Además hay una antología de su obra editada por la empresa Zig-Zag de Chile en 1942.

8 Emilio Oribe. Obras: Las letanias extrañas, El nardo del ánfora, El castillo interior, El nunca usado mar, La colina del pájaro rojo, La transfiguración del cuerpo, Avión de sueños, Los altos mitos, El rosal y la esfera, La serpiente y el tiempo, El canto del cuadrante, La salamandra. Obras en prosa: Poética y plástica y Teoría del nous. Su obra se encuentra repartida entre 1912 y los días que corren.

9 Jesualdo. (Nombre literario de Jesualdo Sosa.) Obras: Nave de alba pura, 1927. El hermano Polichinela, 1929. Siembra de pájaros (doce canciones musicadas por el maestro J. Tomás Mújica), Vida de un maestro (novela), 1935, (primera edición, habiendo alcanzado seis en la actualidad). 180 Poemas de los niños, de Jesualdo (antología infanti1), 1938. Artigas (biografía novelada), 1940. Sinfonía de la danzarina, 1942. Los fundamentos de la nueva pedagogía, 1943. Problemas de la educación, 1943. José Artigas (biografía novelada del héroe, para uso de los niños), 1944. La literatura infantil, 1943. 500 Poemas de los niños, de Jesualdo, 1945, 17 educadores de América, 1945. La enseñanza en el Uruguay, 1947. La expresión creadora del niño, 1950. Elegía autobiográfica, 1949. Don Juan, de Byron, 1955.

10 Juan Cunha Dotti. Obras: El pájaro que vino de la noche, 1929. Guardián oscuro y Tres cuadernos de poesía, 1937. Cuaderno de nubes, 1945. Seis sonetos humanos, 1948. En pie de arpa, 1950. Sueño y retorno de un campesino, 1951. Variación de Rosania, 1952. Cancionero de pena y luna, 1953. Triple tentativa, 1954. 
11 Sara de Ibáñez. Obras: Canto, 1940. Canto a Montevideo, 1941. Hora ciega, 1949.

12 Denis Molina. Obras: Fundamentalmente teatro.

13 Idea Vilariño. Obras: La suplidante, 1945. Cielo, cielo, 1947. Paraiso perdido, 1949. 1950.

14 Carlos Brandy. Obras: Rey humo, 1948. La espada desenvainada,

15 Saúl Pérez. Obras: Homo ciudad, 1950.

16 Ariel Badano. Obras: Cantos generales, 1947. Voces del hombre, 1949. 